\title{
HYPOCALCAEMIA DUE TO 22q11.2 DELETION SYNDROME DIAGNOSED IN ADULTHOOD
}

\author{
Maria Cabrer Vidal, Guillermo Serra Soler, Marzena Wos, María Soledad Gogorza Pérez, \\ Iñaki Argüelles Jiménez, Santiago Tofé Povedano, Elena Mena Ribas, Honorato García \\ ::: \\ Fernández, Vicente Pereg Macazaga
}

Hospital Universitari Son Espases, Palma de Mallorca, Spain

\section{INTRODUCTION}

Hypocalcaemia is present in half of the patients with 22q11.2 deletion syndrome (DiGeorge-velocardiofacial syndrome $)^{1}$. Most of these cases are diagnosed during childhood.

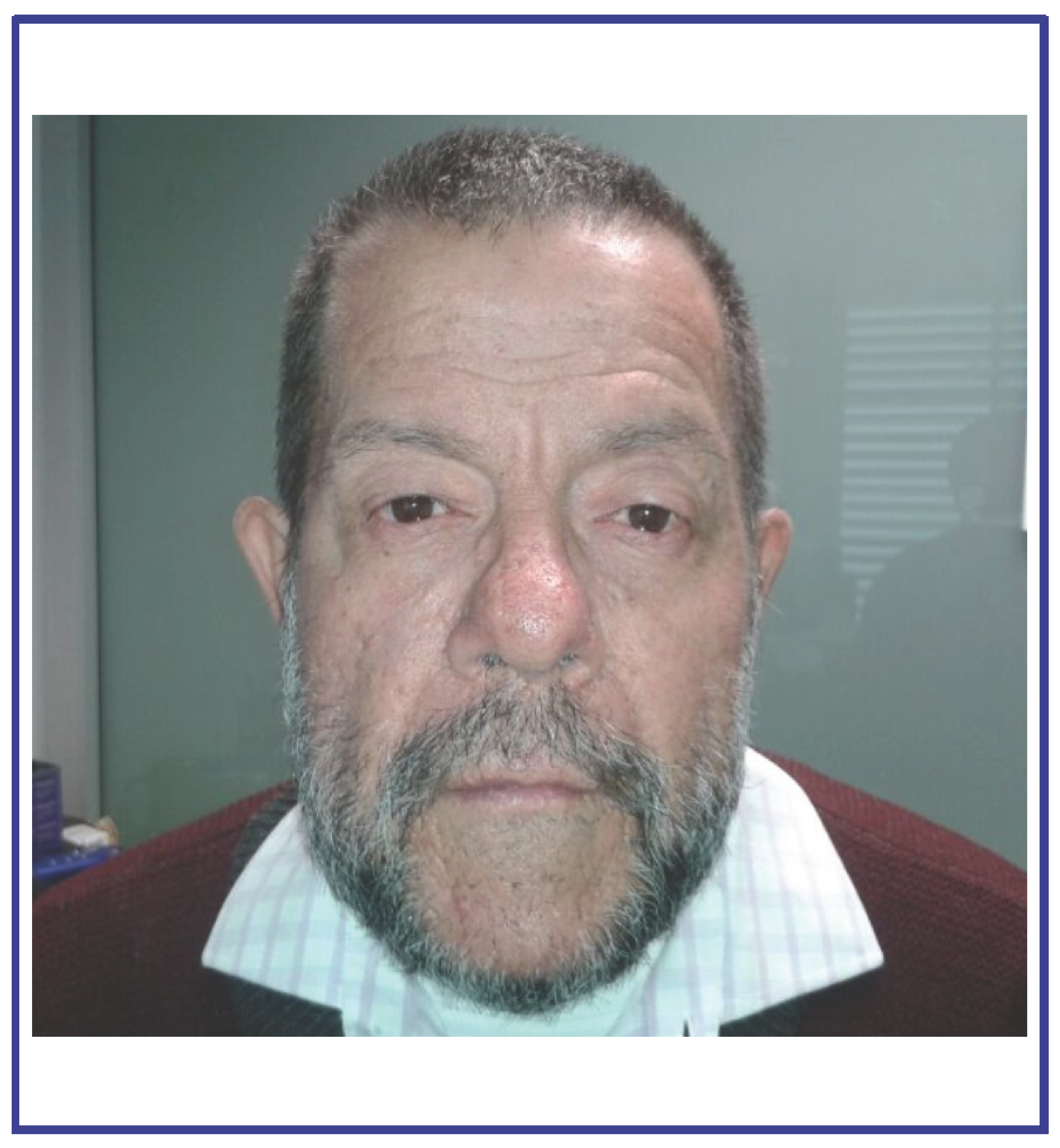

CONCLUSIONS

It is important to classify hypocalcaemia diagnosed at any age. This is especially relevant in hypocalcaemias caused by genetic syndromes like in this case, as it can lead to $50 \%$ risk of an affected offspring.

\section{CASE REPORT}

A 56-year-old man was evaluated for symptomatic hypocalcaemia after undergoing a left nephrectomy because of renal tumour. He had paraesthesia around his mouth and hands and a positive Trousseau's sign. His past medical history included high blood pressure, type 2 diabetes, dyslipaemia and chronic obstructive pulmonary disease. He mentioned a hypocalcaemia episode 10 years ago, frequent bronchitis at childhood and learning difficulties.

Blood tests showed hypocalcaemia of $6.2 \mathrm{mg} / \mathrm{dl}$ (NV: 8.4-10.2) hypoalbuminaemia of 29,7g/l, (35-50 g/l), corrected calcium of $7.08 \mathrm{mg} / \mathrm{dl}$, hyperphosphatemia of $4.8 \mathrm{mg} / \mathrm{dl}$ (2.3-4.7) and normal magnesium. Parathyroid hormone (PTH) was $11 \mathrm{pg} / \mathrm{ml}$ (15-88), 25-hydroxy vitamin D $16 \mathrm{pg} / \mathrm{ml}(>30)$ and 1.25dihydroxy vitamin D $20.1 \mathrm{pg} / \mathrm{ml}$ (26.1-95). Thyroid function was normal. The electrocardiogram showed no prolonged QT interval. Endovenous and oral calcium and calcitriol were initiated, with normalization of calcium levels.

Based on hypocalcaemia secondary to primary hypoparathyroidism, anti-parathyroid and calcium sensor receptor antibodies were requested. Due to childhood medical history and dysmorphic phenotype (hooded eyelid, bulbous nasal tip) a genetic test of 22q11.2 deletion was requested. Anti-parathyroid antibodies were negative and calcium sensor receptor antibodies were finally not made. The genetic test confirmed the diagnosis, so more tests were made in the outpatient clinic.

Treatment at discharge was oral calcium and calcitriol. Echocardiography was normal. Densitometry revealed no bone mass loss. Immunologic studies showed a mild disturbance of cellular immunity. He received genetic advice of affected offspring.

\section{References}

1. Lima K, Abrahamsen TG, Wolff AB, Husebye E, Alimohammadi M, Kämpe O, et al. Hypoparathyroidism and autoimmunity in the 22q11.2 deletion syndrome. Eur J Endocrinol Eur Fed Endocr Soc. agosto de 2011;165(2):345-52 